\title{
Importance of the agar-media in the evaluation of bacteriocin activity against the same test-microorganisms
}

\author{
Pamela Oliveira de Souza de Azevedo ${ }^{1}$, Francesco Molinari², Ricardo Pinheiro de Souza Oliveira ${ }^{1 *}$
}

${ }^{1}$ Department of Biochemical and Pharmaceutical Technology, Faculty of Pharmaceutical Sciences, University of São Paulo, São Paulo, SP, Brazil, ${ }^{2}$ Department of Food, Environmental and Nutritional Sciences (DeFENS), Section of Food Microbiology and Bioprocesses, University of Milan, Milan, Italy

\begin{abstract}
Bacteriocins are peptides produced by various species of bacteria, especially lactic acid bacteria, which exhibit a large spectrum of action against spoilage bacteria and foodborne pathogens. Successful application of techniques for quantitative or qualitative bacteriocin determination relies not only on the sensitivity of the test-microorganisms, but also on the agar-medium employed. Cell free supernatants are routinely used to preliminary screen for antimicrobial activity of bacteria by means of the agar well diffusion method, but the supernatant may also include other molecules (such as medium components and/or intracellular compounds) accidentally released during cell free supernatant preparation, which may interfere with the assay. Reproducibility of bacteriocin activity against the same test-microorganisms is an important factor to be considered. Unfortunately, no specific information about bioassays standardization to determine bacteriocin activity is available in the literature. In this work, growth inhibition by means of the agar well diffusion assays were carried out on different agar-media showing a strong dependence on the agar-medium used, indicating that the inhibitory effects could also depend on the diffusion of exudates that are included in the cell-free supernatant. The results presented in this communication show that selection of the agar-medium is crucial for the bioassay response.
\end{abstract}

Keywords: Bacteriocin. Growth inhibition. Solid medium. Agar well diffusion assay

\section{INTRODUCTION}

Bacteriocins are small and cationic antimicrobial peptides, ribosomally synthesized by lactic acid bacteria (LAB) (Singh, Ghosh, 2012), with antilisterial activity (Papagianni, Sergelidis, 2015) and many industrial applications (Papagianni, 2003). The industrial importance of LAB is further demonstrated by their status generally recognized as safe (GRAS) (Fan, Song, 2013). Additionally, lactic acid and other metabolic products produced by LAB contribute to the organoleptic and textural profile, as well as shelf life of food products (Ross, Morgan, Hill, 2002), especially the ones produced from fermented milk cultures concerning the control of foodborne pathogens (Porto et al., 2017).

Several pediocins, the bacteriocins produced by Pediococcus pentosaceus spp., have been characterized

\footnotetext{
*Correspondence: R. P. S. Oliveira. Departamento de Tecnologia BioquímicoFarmacêutica, Faculdade de Ciências Farmcêuticas, Universidade de São Paulo. Phone: +55 113091 0123; fax: +55 113815 6386. E-mail: rpsolive@usp.br
}

(Papagianni, Anastasiadou, 2009) and they are amongst the most promising bacteriocin in the industry (Turcotte et al., 2004) as food preservative (Bharti et al., 2015). They have structural similarities, but different spectrum of antimicrobial activity (Papagianni, Sergelidis, 2015). Pediocins exhibit important technological properties such as thermostability and the capacity of retaining activity at a wide range of $\mathrm{pH}$ with bactericidal action especially against Gram-positive food spoilage and pathogenic bacteria; these features make pediocins an important class of biopreservatives (Papagianni, Anastasiadou, 2009).

P. pentosaceus ATCC 43200, also known as FBB61, was isolated in 1953 from cucumber fermentation and produced pediocin A (Fleming, Etchells, Costilow, 1975), which was shown to belong to the class III bacteriocins (Klaenhammer, 1993), with molecular weight of 80 $\mathrm{kDa}$ and a broad range of activity against Gram-positive bacteria (Piva, Headon, 1994).

A major difficulty in antimicrobial peptide research and application is their identification and quantification using bioassays (Choyam et al., 2015). Agar diffusion 
assay, that produces halos, where growth is inhibited, is undoubtedly the most commonly used method to determine bacteriocin activity (Bouksaim et al., 2000). However, this methodology is dependent on the bacteriocin diffusing through the agar, which is time-consuming and also relies on human interpretation when zones of inhibition are unclear or not perfectly circular (Papagianni et al., 2006). The possibility of unspecific reaction between the active substance present in the tested culture and the agarmedium should also be considered.

The purpose of this work was to illustrate seemingly just how variable zones of inhibition can be when bacteriocin activity against Enterococcus spp., Listeria spp. and Escherichia coli was assessed using agar diffusion test performed in different types of agar-media.

\section{MATERIAL AND METHODS}

\section{Bacterial strains and growth conditions}

P. pentosaceus ATCC $43200\left(\mathrm{OD}_{600 \mathrm{~nm}}=0.8-0.9\right)$ (Halo VIS-10, Dynamica, Australian) was grown at 30 ${ }^{\circ} \mathrm{C}$, stirring at $100 \mathrm{rpm}$ (TE-420, Tecnal, Piracicaba, SP, Brazil), in $100 \mathrm{~mL}$ of pH 6.5 Man, Rogosa and Sharpe (MRS) medium (Difco Laboratories, Detroit, MI, USA), which contains $2.0 \%(\mathrm{w} / \mathrm{v})$ as main C-source (G-MRS). It was supplemented with either $1.0 \%(\mathrm{w} / \mathrm{v})$ inulin (Orafti ${ }^{\circledR} \mathrm{GR}$, Orafti Active Food Ingredients, Oreye, Belgium) (GI-MRS), $1.0 \%(\mathrm{w} / \mathrm{v})$ sucrose (GS-MRS), $1.0 \%(\mathrm{w} / \mathrm{v})$ inulin and $1.0 \%(\mathrm{w} / \mathrm{v})$ sucrose (GSI-MRS); alternatively, $2.0 \%(\mathrm{w} / \mathrm{v})$ inulin (I-MRS) and 2.0\% (w/v) sucrose (S-MRS) were used as the sole carbon source. Aliquots were taken every $2 \mathrm{~h}$ during the first $12 \mathrm{~h}$ of the cultivation, and thereafter at $24 \mathrm{~h}$ and $48 \mathrm{~h}$.

Enterococcus spp. (strains Ent101, Ent104 and Ent711), Listeria innocua (strains Li2052 and Li2865) were grown in Brain Heart Infusion (BHI) medium (Difco). Escherichia coli ATCC 25922 was grown in Tryptic Soy (TSB) Broth (Difco). One $\mathrm{mL}$ of each cryopreserved bacterium was grown in $5.0 \mathrm{~mL}$ medium for $16 \mathrm{~h}$ at $37{ }^{\circ} \mathrm{C}$ without stirring (TE-310, Tecnal, Piracicaba, SP, Brazil). The cultures were then diluted with sterile deionized water to provide an optical density of $600 \mathrm{~nm}$ for 0.3 .

\section{Bacteriocin activity determination}

P. pentosaceus cells were collected by centrifugation ( $4.470 \mathrm{x} g$ at $4^{\circ} \mathrm{C}$ for $15 \mathrm{~min}$ ) and the cell-free supernatant was adjusted to $\mathrm{pH} 6.0-6.5$ by the addition of $1.0 \mathrm{~N} \mathrm{NaOH}$, heated to $70{ }^{\circ} \mathrm{C}$ for $25 \mathrm{~min}$ to inactivate proteases and filtered $(0.45 \mu \mathrm{m}$ pore diameter filter, Millipore, Billerica,
MA, USA). The agar well diffusion assay was performed using $200 \mu \mathrm{L}$ of each indicator strain suspension $(\mathrm{OD}=0.3)$ (Halo VIS-10, Dynamica, Australian) added to $20.0 \mathrm{~mL}$ of medium supplemented with $1.0 \%(\mathrm{w} / \mathrm{v})$ agar and poured into Petri dishes. Fifty $\mu \mathrm{L}$ of each denatured supernatant was added into each well. All plates were incubated for $16-18 \mathrm{~h}$ at $37^{\circ} \mathrm{C}$ (TE-310, Tecnal, Piracicaba, SP, Brazil) in duplicate. The agar-media evaluated were BHI and Mueller Hinton to Enterococcus and Listeria strains and TSB and MacConkey to E. coli.

\section{Statistical analysis}

One-way analysis of variance (ANOVA) and Tukey's test by Microsoft Excel (Redmond, WA, USA) were performed and a significant difference was defined as a $p$ value $<0.05$.

\section{RESULTS AND DISCUSSION}

The production of bacteriocin is dependent on the type of nutrient sources present in the medium (Todorov, Dicks, 2004) and to confirm the unsuitability of sucrose and inulin as the only carbon source for this P. pentosaceus strain, as demonstrated by de Souza de Azevedo et al. (2017), both these carbon sources were used to supplement the MRS medium. As a result, glucose is shown as the most important carbon source that $P$. pentosaceus ATCC 43200 metabolizes.

The antimicrobial activity of bacteriocin extract produced by $P$. pentosaceus grown in different culture media was assessed by agar well diffusion assay, performed on Mueller Hinton and MacConkey (E. coli) agar-media, after $24 \mathrm{~h}$ cultivation against Enterococcus spp. (strains Ent101, Ent104 and Ent711), Listeria innocua (strains Li2052 and Li2865) and E. coli ATCC 25922, taken as examples of Gram-positive and Gram-negative microorganisms. L. innocua strains were sensitive to the cultivation supernatant of GI-MRS and GS-MRS collected after $24 \mathrm{~h} \mathrm{(21-22} \mathrm{mm} \mathrm{diameter),} \mathrm{about} \mathrm{26 \%} \mathrm{larger} \mathrm{than}$ supernatants of other media. E. coli was sensitive to the cultivation supernatant of G-MRS, S-MRS and I-MRS media $(17.3 \mathrm{~mm})$, on average $6.5 \%$ greater than Ent711 to the same supernatant (Table I). Figure 1 demonstrates the aspect of the inhibition halos of bacteriocin extract produced by $P$. pentosaceus in G-MRS after $24 \mathrm{~h}$ of cultivation when the assays were performed on Mueller Hinton and MacConkey agar-media.

The reproducibility of these results performed on Muller Hinton and MacConkey agar-media (Table I; Figure 1) was also assessed by comparing the activity 
TABLE I - Antimicrobial activity (mm) of bacteriocin extract produced by $P$. pentosaceus ATCC 43200 cultivated in different media and collected at $24 \mathrm{~h}$. The assays were performed on Mueller Hinton (Enterococcus and Listeria) and MacConkey (E. coli) agar-media

\begin{tabular}{llcccccc}
\hline & & \multicolumn{7}{c}{ Antimicrobial activity } \\
\hline Time (h) & Indicator strains & G-MRS & GS-MRS & GI-MRS & S-MRS & I-MRS & GSI-MRS \\
\hline \multirow{4}{*}{24} & Enterococcus sp. 101 & $12.10 \pm 0.14^{\mathrm{a}}$ & $12.05 \pm 0.07^{\mathrm{a}}$ & $12.00 \pm 0.02^{\mathrm{a}}$ & $11.60 \pm 0.14^{\mathrm{a}}$ & $11.00 \pm 0.02^{\mathrm{a}}$ & $13.45 \pm 0.07^{\mathrm{d}}$ \\
& Enterococcus sp. 104 & $12.65 \pm 0.07^{\mathrm{b}}$ & $13.35 \pm 0.07^{\mathrm{b}}$ & $13.20 \pm 0.14^{\mathrm{c}}$ & $13.90 \pm 0.14^{\mathrm{b}}$ & $13.00 \pm 0.03^{\mathrm{b}}$ & $12.55 \pm 0.07^{\mathrm{c}}$ \\
& Enterococcus sp. 711 & $15.40 \pm 0.14^{\mathrm{c}}$ & $12.05 \pm 0.07^{\mathrm{a}}$ & $12.00 \pm 0.02^{\mathrm{a}}$ & $16.40 \pm 0.14^{\mathrm{d}}$ & $16.60 \pm 0.14^{\mathrm{e}}$ & $12.00 \pm 0.02^{\mathrm{a}}$ \\
& Listeria innocua 2052 & $16.50 \pm 0.01^{\mathrm{d}}$ & $22.00 \pm 0.04^{\mathrm{d}}$ & $20.05 \pm 0.07^{\mathrm{d}}$ & $16.00 \pm 0.11^{\mathrm{c}}$ & $15.00 \pm 0.04^{\mathrm{c}}$ & $16.00 \pm 0.04^{\mathrm{f}}$ \\
& Listeria innocua 2865 & $18.00 \pm 0.02^{\mathrm{e}}$ & $20.00 \pm 0.03^{\mathrm{c}}$ & $21.35 \pm 0.07^{\mathrm{e}}$ & $17.00 \pm 0.04^{\mathrm{e}}$ & $16.00 \pm 0.05^{\mathrm{d}}$ & $13.90 \pm 0.14^{\mathrm{e}}$ \\
& Escherichia coli ATCC & $16.60 \pm 0.14^{\mathrm{d}}$ & $12.10 \pm 0.14^{\mathrm{a}}$ & $13.00 \pm 0.05^{\mathrm{c}}$ & $17.00 \pm 0.04^{\mathrm{e}}$ & $18.45 \pm 0.07^{\mathrm{f}}$ & $12.50 \pm 0.01^{\mathrm{b}}$ \\
& 25922 & & & & & & \\
\hline
\end{tabular}

Legend: G-MRS = glucose-based MRS medium, GS-MRS = glucose + sucrose-based MRS medium, GI-MRS = glucose + inulinbased MRS medium, S-MRS = sucrose-based MRS medium, I-MRS = inulin-based MRS medium, GSI-MRS = glucose + sucrose + inulin-based MRS medium. Mean values $(\mathrm{n}=3) \pm$ standard deviations. Different letters in the same column mean that values significantly differ among them $(p<0.05)$.

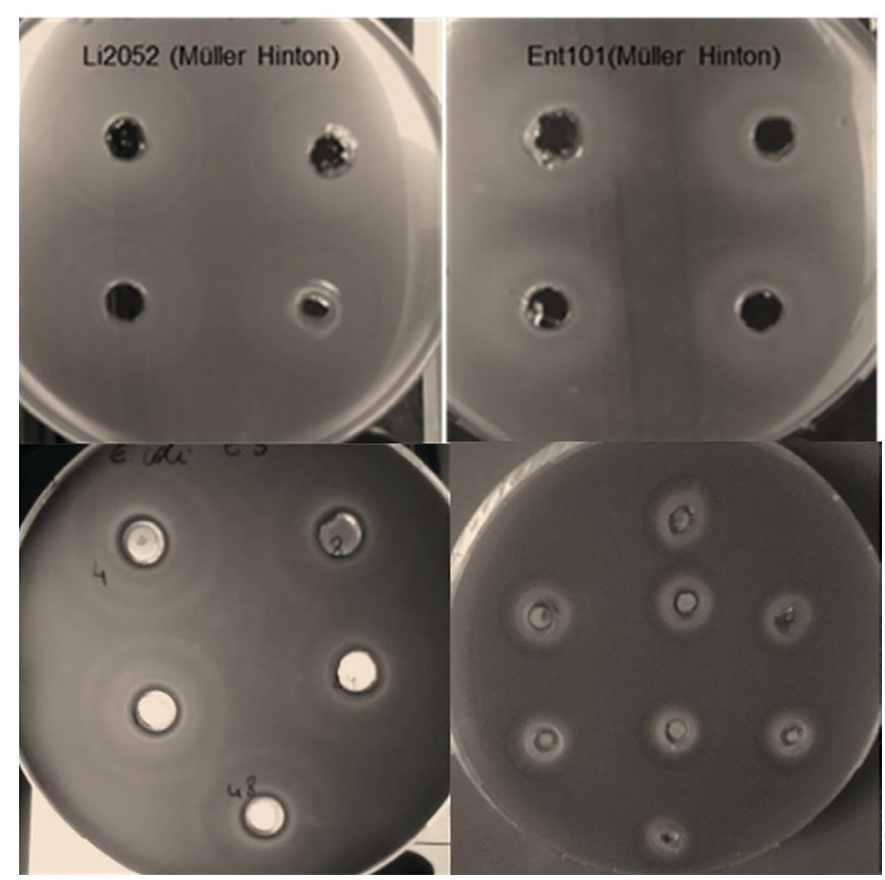

FIGURE 1 - Antimicrobial activity of bacteriocin extract produced by Pediococcus pentosaceus ATCC 43200 after 24 $\mathrm{h}$ of cultivation in G-MRS medium against Listeria innocua 2052 (Li2052), Enterococcus 101 (Ent101) and Escherichia coli ATCC 25922 (E. coli). Tests were performed by agar-welldiffusion assay carried out on Muller Hinton (Enterococcus and Listeria strains) and MacConkey (E. coli) agar-media. (A, C, E $=$ indicator strain at $\mathrm{OD} 0.3) ;(\mathrm{B}, \mathrm{D}, \mathrm{F}=$ indicator strain diluted 100 times from OD 0.3).

of these supernatants performed on BHI and TSB agarmedia (Table II; Figure 2). It was evident the difference between the aspect and the diameters of the inhibition halos according to the agar-media used in the test. Enterococcus and Listeria strains were susceptible to the antimicrobial activity of supernatants $(24 \mathrm{~h})$ but the aspect and the diameters of the halos were not related to Muller Hinton and BHI agar-media. As expected, there was no antimicrobial activity against $E$. coli (Table II) when the test was performed on TSB agar-medium, since Gramnegative bacteria are naturally resistant to the action of bacteriocins produced by Gram-positive bacteria due to their outer membrane (Cao-Hoang, Marechal, Le-Thanh, 2008; Gyawali, Ibrahim, 2014). However, a questionable result could have been considered if this analysis had been carried out only on MacConkey agar-medium, since apparent inhibition halos against $E$. coli were seen only in MacConkey and were not seen in TSB agar-medium.

Among all strains evaluated, there was a significant difference in size of the inhibition halos according to the culture media used for the bacteriocin extract production (Table I; Table II), however, the most noteworthy observation that should be highlighted was the absence of inhibition halo against $E$. coli when the bacteriocin extracts were evaluated on TSB agar-medium.

A possible explanation for these results is the different agar-media composition. There are cations $\left(\mathrm{Ca}^{2+}\right.$ and $\mathrm{Mg}^{2+}$ ) and thymidine in the composition of Mueller Hinton agar-medium, components that are absent in BHI agar-medium, which may have somehow interacted with molecules occurring in the tested supernatants, affecting the obtained results (diameter of inhibition halo). MacConkey is a selective medium for Gram-negative bacteria and, unlike the TSB medium, there are bile salts, neutral red and crystal violet in its composition. In some 
TABLE II - Antimicrobial activity ( $\mathrm{mm}$ ) of bacteriocin extract produced by P. pentosaceus ATCC 43200 cultivated in different media and collected at $24 \mathrm{~h}$. The assays were performed on BHI (Enterococcus and Listeria) and TSB (E. coli) agar-media

\begin{tabular}{llcccccc}
\hline & \multicolumn{7}{c}{ Antimicrobial activity } \\
\hline Time (h) & Indicator strains & G-MRS & GS-MRS & GI-MRS & S-MRS & I-MRS & GSI-MRS \\
\hline \multirow{6}{*}{24} & Enterococcus sp. 101 & $17.95 \pm 0.07^{\mathrm{b}}$ & $17.05 \pm 0.07^{\mathrm{d}}$ & $17.00 \pm 0.02^{\mathrm{e}}$ & $4.60 \pm 0.14^{\mathrm{a}}$ & $4.05 \pm 0.07^{\mathrm{a}}$ & $17.70 \pm 0.14^{\mathrm{c}}$ \\
& Enterococcus sp. 104 & $16.15 \pm 0.21^{\mathrm{a}}$ & $16.10 \pm 0.14^{\mathrm{c}}$ & $16.00 \pm 0.01^{\mathrm{c}}$ & $7.15 \pm 0.21^{\mathrm{b}}$ & $6.00 \pm 0.01^{\mathrm{b}}$ & $16.15 \pm 0.21^{\mathrm{a}}$ \\
& Enterococcus sp. 711 & $16.00 \pm 0.12^{\mathrm{a}}$ & $16.15 \pm 0.21^{\mathrm{c}}$ & $16.25 \pm 0.35^{\mathrm{d}}$ & $9.70 \pm 0.01^{\mathrm{d}}$ & $9.65 \pm 0.07^{\mathrm{f}}$ & $16.00 \pm 0.02^{\mathrm{a}}$ \\
& Listeria innocua 2052 & $16.40 \pm 0.34^{\mathrm{a}}$ & $15.00 \pm 0.01^{\mathrm{b}}$ & $13.15 \pm 0.21^{\mathrm{a}}$ & $9.10 \pm 0.14^{\mathrm{c}}$ & $8.05 \pm 0.07^{\mathrm{c}}$ & $16.00 \pm 0.02^{\mathrm{a}}$ \\
& Listeria innocua 2865 & $16.45 \pm 0.17^{\mathrm{a}}$ & $13.00 \pm 0.02^{\mathrm{a}}$ & $14.40 \pm 0.14^{\mathrm{b}}$ & $10.10 \pm 0.14^{\mathrm{e}}$ & $9.00 \pm 0.02^{\mathrm{e}}$ & $15.05 \pm 0.07^{\mathrm{b}}$ \\
& Escherichia coli ATCC & - & - & - & - & - & - \\
& 25922 & & & & & & \\
\hline
\end{tabular}

Legend: G-MRS = glucose-based MRS medium, GS-MRS = glucose + sucrose-based MRS medium, GI-MRS = glucose + inulinbased MRS medium, S-MRS = sucrose-based MRS medium, I-MRS = inulin-based MRS medium, GSI-MRS = glucose + sucrose + inulin-based MRS medium. Mean values $(n=3) \pm$ standard deviations. Different letters in the same column mean that values significantly differ among them $(p<0.05)$.

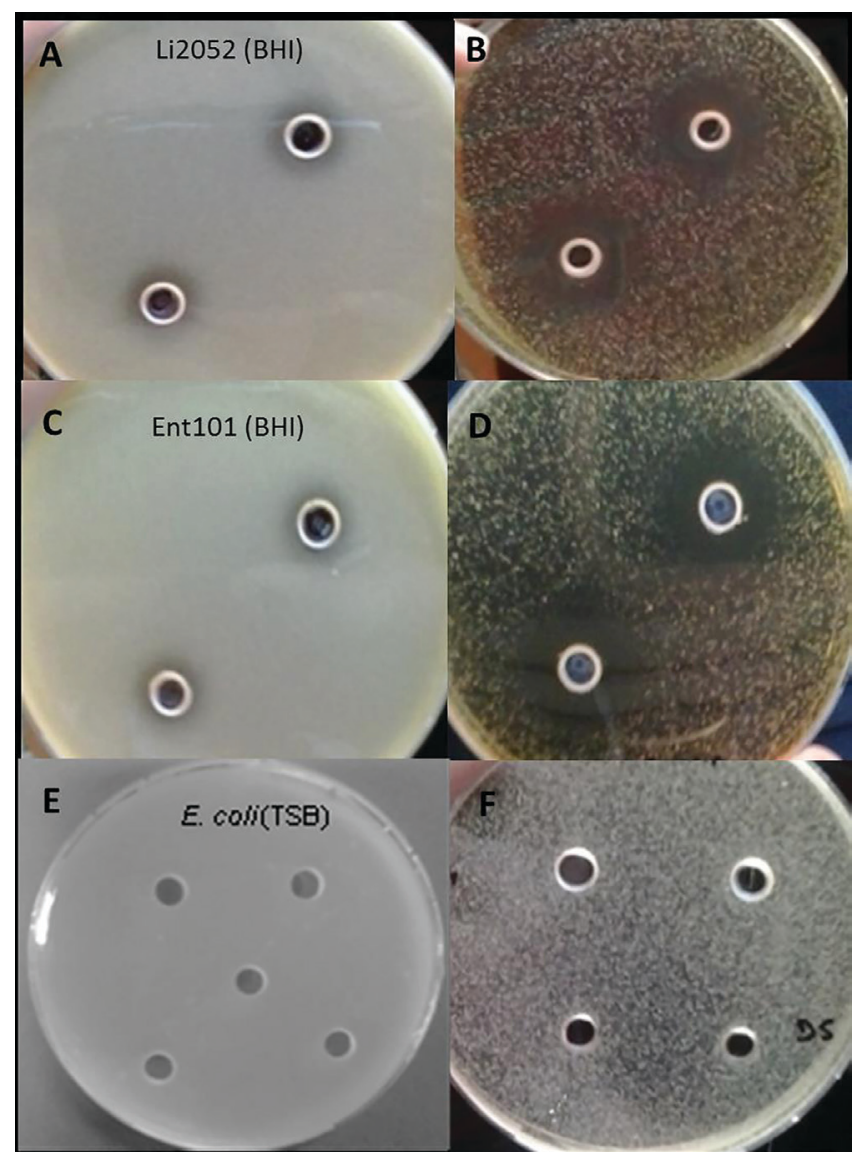

FIGURE 2 - Antimicrobial activity of bacteriocin extract produced by Pediococcus pentosaceus ATCC 43200 after $24 \mathrm{~h}$ of cultivation in G-MRS medium against Listeria innocua 2052 (Li2052), Enterococcus 101 (Ent101) and Escherichia coli ATCC 25922 (E. coli). Tests were performed by agar-well-diffusion assay carried out on BHI (Enterococcus and Listeria strains) and TSB (E. coli) agar-media. (A, C, E = indicator strain at OD 0.3); (B, D, F = indicator strain diluted 100 times from OD 0.3). way, the tested supernatants could interact with one of these different components present in MacConkey agarmedium, hence producing false positive results as shown in Figure 2.

Currently, it is difficult to find comparison in the literature about using bioassays performed only in solid (agar) medium as presented in this work, meanwhile it is possible to find tests performed either in solid (agar diffusion assay) or in liquid (turbidimetry) media more easily. A major difficulty in bacteriocin research is obtaining accurate results using bioassays, which are based in inhibition activity produced in a sensitive microorganism (Rasch, Knochel, 1998; Papagianni et al., 2006).

Using the agar spot assay, a method also performed on agar-medium and very similar to agar well diffusion assay, Arena et al. (2016) identified strong inhibition effect of seventeen Lactobacillus plantarum strains according to the classification made by Gaudana, Dhanani and Bagchi (2010), showing inhibition halos of greater than $5 \mathrm{~mm}$ against the majority of food pathogens tested. The antimicrobial activity of the tested $L b$. plantarum strains were mostly observed when they were grown on solid media, rather than brought into contact with pathogenic bacteria. To the performed well diffusion assay, the antimicrobial capability was confirmed when the cellfree supernatant (CFS) was concentrated ten-fold, thus indicating that a minimal concentration of antimicrobial compounds was required to sustain similar inhibition results (Arena et al., 2016).

The CFS may also include other molecules besides those secreted by bacteria such as medium components and/or intracellular compounds, which may be accidentally 
released during CFS preparation (Arena et al., 2016). Despite this possibility, CFS are routinely used to preliminary screen for antimicrobial activity of bacteria by well diffusion method (Kassaa et al., 2014; Wang et al., 2014). This indicates that the inhibitory effects mainly depend on exudates, which are included in the CFS (Arena et al., 2016).

Other investigations observed that indicator cultures showed different sensitivity in agar and in liquid medium. The results of these investigations suggested a greater capability of CFSs to contrast pathogenic bacteria in liquid-medium in comparison to agar-medium (Saadatzadeh et al., 2013). Compared with Lactobacillus curvatus, Listeria monocytogenes and Listeria seeligeri, they were more sensitive to bacteriocin action on agarmedium than in liquid-medium and bacteriocins showed a greater activity against $L b$. curvatus in liquid-medium than in agar-medium (Coventry et al., 1997). In another investigation with nine test-microorganisms used, only two of them, Lb. curvatus ATCC 51436 and P. acidilactici ATCC 25740, were sensitive to very low bacteriocin (nisin) concentrations and produced a linear type of response either in agar-medium (agar diffusion assay) or liquid-medium (turbidometric assay) (Papagianni et al., 2006).

The results presented in this work indicated different measurements of bacteriocin activity to the same testmicroorganisms when the assays were performed in different solid medium (agar diffusion assay). These data suggest that any compared data in the literature must always be performed among identical methods, highlighting the need to choose carefully the agar-medium used in bacteriocin research.

\section{ACKNOWLEDGMENTS}

Financial support for this project was provided by FAPESP (grant 2016/06284-9 to RPSO) and CAPES (grant 1560096 to POSA).

\section{CONFLICT OF INTEREST}

The authors declare that they have no conflict of interest.

\section{REFERENCES}

Arena MP, Silvain A, Normanno G, Grieco F, Drider D, Spano G, et al. Use of Lactobacillus plantarum Strains As A Bio-Control Strategy Against Food-Borne Pathogenic Microorganisms. Front Microbiol. 2016;7(464):1-10.
Bharti V, Mehta A, Singh S, Neha J, Ahirwal L, Mehta S. Bacteriocin: a novel approach for preservation of food. Int J Pharm Pharm Sci. 2015;7(9):20-9.

Bouksaim M, Lacroix C, Audet P, Simard RE. Effects of mixed starter composition on nisin $\mathrm{Z}$ production by Lactococcus lactis subsp. lactis biovar. diacetylactis UL 719 during production and ripening of Gouda cheese. Int J Food Microbiol. 2000;59(3):141-56.

Cao-Hoang L, Marechal PA, Le-Thanh M. Synergistic action of rapid chilling and nisin on the inactivation of Escherichia coli. Appl Microbiol Biotechnol. 2008;79(1):105-109.

Choyam S, Lokesh D, Bheemakere KB, Kammara R. Assessing the antimicrobial activities of Ocins. Front Microbiol. 2015;6(1034):1-10.

Coventry MJ, Gordon JB, Wilcock A, Harmark K, Davidson BE, Hickey MW, et al. Detection of bacteriocins of lactic acid bacteria isolated from foods and comparison with pediocin and nisin. J Appl Microbiol. 1997;83(2):248-58.

de Souza de Azevedo PO, Converti A, Domínguez JM, de Souza Oliveira RP. Stimulating effects of sucrose and inulin on growth, lactate and bacteriocin productions by Pediococcus pentosaceus. Probiotics Antimicrobial Proteins. 2017. Doi: 10.1007/s12602017-9292-8.

Fan L, Song J. Antimicrobial microbes-bacteriocin producing lactic acid bacteria. In: Méndez-Vilas A, editor. Microbial pathogens and strategies for combating them: science, technology and education. Spain: Formatex Research Center; 2013. v.2, 899-909.

Fleming HP, Etchells JL, Costilow RN. Microbial inhibition by an isolate of Pediococcus from cucumber brines. Appl Microbiol. 1975;30(6):1040-104.

Gaudana SB, Dhanani AS, Bagchi T. Probiotic attributes of Lactobacillus strains isolated from food and of human origin. Br J Nutr. 2010;103(11):1620-28.

Gyawali R, Ibrahim SA. Natural products as antimicrobial agents. Food Control. 2014;46:412-429.

Kassaa IA, Hober D, Hamze M, Chihib NE, Drifer D. Antiviral potential of lactic acid bacteria and their bacteriocins. Prob Antimicrob Prot. 2014;6(3-4):177-85. 
Klaenhammer TR. Genetics of bacteriocins produced by lactic acid bacteria. FEMS Microbiol Rev. 1993;12(1-3):39-85.

Papagianni M. Ribosomally synthesized peptides with antimicrobial properties: biosynthesis, structure, function, and applications. Biotechnol Adv. 2003;21(6):465-99.

Papagianni M, Avramidis N, Filioussis G, Dasiou D, Ambrosiadis I. Determination of bacteriocin activity with bioassays carried out on solid and liquid substrates: assessing the factor "indicator microorganism”. Microb Cell Fact. 2006;5(30):1-10.

Papagianni M, Anastasiadou S. The bacteriocins of pediococci. Microb Cell Fact. 2009;8(3):1-10.

Papagianni M, Sergelidis D. Chemostat production of pediocin SM-1 by Pediococcus pentosaceus Mees 1934. Biotechnol Prog. 2015;31(6):1481-86.

Piva A, Headon DR. Pediocin A, a bacteriocin produced by Pediococcus pentosaceus FBB61. Microbiol. 1994;140(pt. 4):697-702.

Porto, MCW, Kuniyoshi, TM, Azevedo, POS, Vitolo, M, Oliveira, RPS. Pediococcus spp.: An important genus of lactic acid bacteria and pediocin producers. Biotechnol Adv. 2017;35(3):361-374.

Rasch M, Knochel S. Variations in tolerance of Listeria monocytogenes to nisin, pediocin PA-1 and bavaricin A. Appl Microbiol. 1998;27(5):275-78.
Ross RP, Morgan S, Hill C. Preservation and fermentation: past, present and future. Int J Food Microbiol. 2002;79(1-2):3-16.

Saadatzadeh A, Fazeli MR, Jamalifar H, Dinarvand R. Probiotic properties of lyophilized cell free extract of Lactobacillus casei. Jundishapur J Nat Pharm Prod. 2013;8(3):131-37.

Singh J, Ghosh C. Ribosomal encoded bacteriocins: their functional insights and applications. J Microbiol Res. 2012;2(2):19-25.

Todorov SD, Dicks LMT. Effect of medium components on bacteriocin production by Lactobacillus pentosus ST151BR, a strain isolated from beer produced by the fermentation of maize, barley and soy flour. World J Microbiol Biotechnol. 2004;20(6):643-650.

Turcotte C, Lacroix C, Kheard E, Grignon L, Fliss I. A rapid turbidometric microplate bioassays for accurate quantification of lactic acid bacteria bacteriocins. Int J Food Microbiol. 2004;90(3):283-293.

Wang G, Zhao Y, Tian F, Jin X, Chen H, Liu X, et al. Screening of adhesive lactobacilli with antagonistic activity against Campylobacter jejuni. Food Control. 2014;44:49-57.

Received for publication on $28^{\text {th }}$ August 2017 Accepted for publication on $11^{\text {th }}$ September 2017 